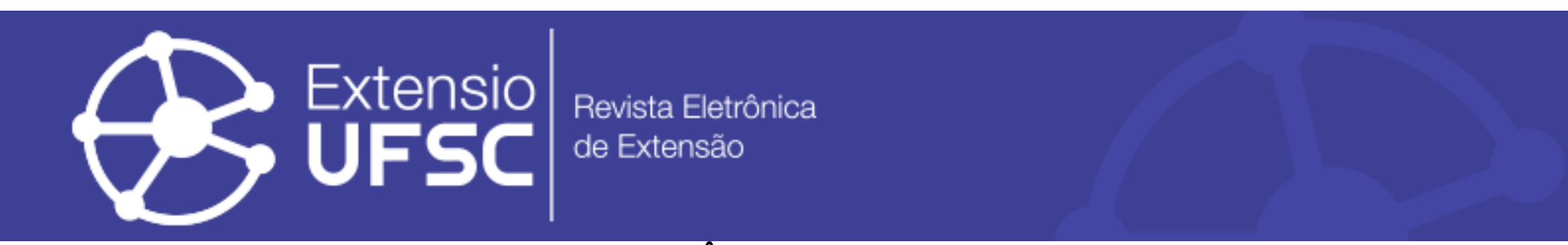

\title{
RELATO DA EXPERIÊNCIA DO PROJETO SiEM NA UFSC
}

\author{
Patricia Fonseca Ferreira Arienti \\ Universidade Federal de Santa Catarina \\ pffarienti@gmail.com \\ Carolina Veras Micheletti \\ Universidade Federal de Santa Catarina \\ carolvtti@gmail.com
}

\author{
Davi Antunes da Luz \\ Universidade Federal de Santa Catarina \\ antunnesdavi@gmail.com \\ João Paulo Cavazzani Bosso \\ Universidade Federal de Santa Catarina \\ jpaulobosso@gmail.com
}

Leonardo Felipe Santos de Souza Universidade Federal de Santa Catarina leosfsouza55@gmail.com

\section{Resumo}

A Simulação de Organizações Internacionais para alunos do Ensino Médio (SiEM) é um projeto de extensão, realizado na Universidade Federal de Santa Catarina que busca simular as principais mesas de debate e tomadas de decisão nas organizações internacionais, tais como a Assembleia Geral da ONU, a União Europeia, o Conselho de Segurança das Nações Unidas, entre outras. O objetivo é estimular seus participantes a aprofundar conhecimentos nas mais variadas áreas do saber, como Política Internacional, Meio Ambiente, Comércio Internacional, História e Direito. O projeto é direcionado ao estudante de ensino médio do estado de Santa Catarina. Ressalta-se que é um projeto inteiramente gratuito para todos os estudantes participantes, o que possibilita a participação de estudantes de escolas tanto da rede privada, quanto da rede pública.

Palavras-chave: Extensão; Ensino Médio; Simulação.

\section{REPORT ON THE EXPERIENCE OF THE SiEM PROJECT AT UFSC}

\begin{abstract}
The Simulation of International Organizations for High School Students (SiEM) is an extension project, carried out at the Federal University of Santa Catarina, in Brazil. It seeks to simulate the main debate tables and decision-making in international organizations, such as the UN General Assembly, the European Union, the United Nations Security Council, among others. The objective is to encourage its participants to deepen their knowledge in the most varied areas of expertise, such as International Politics, Environment, International Trade, History, and Law. The project is aimed at high school students in the state of Santa Catarina. It is noteworthy that it is a completely free project, allowing the participation of students from both private and public schools.
\end{abstract}

Keywords: Extension; High School; Simulation.

\section{INFORME SOBRE LA EXPERIENCIA DEL PROYECTO SIEM EN UFSC}

\section{Resumen}

La Simulación de Organismos Internacionales para Estudiantes de Bachillerato (SiEM) es un proyecto de extensión, realizado en la Universidad Federal de Santa Catarina, que busca simular las principales mesas de debate y toma de decisiones en organismos internacionales, como la Asamblea General de la ONU, la Unión Europea, el Consejo de Seguridad de Naciones Unidas, entre otros. El objetivo es incentivar a sus participantes a profundizar sus conocimientos en las más variadas áreas del conocimiento, tales como Política Internacional, Medio Ambiente, Comercio Internacional, Historia y Derecho. El proyecto está dirigido a estudiantes de secundaria del estado de Santa Catarina. Cabe destacar que se trata de un proyecto completamente gratuito para todos los alumnos participantes, lo que permite la participación de alumnos de colegios tanto privados como públicos.

Palabras clave: Extensión; Escuela Secundaria; Simulación. 


\section{INTRODUÇÃO}

O SiEM - Simulação de Organizações Internacionais para o Ensino Médio - é um projeto de extensão do curso de Relações Internacionais da Universidade Federal de Santa Catarina, no qual estudantes secundaristas são convidados a participar de simulações das principais Organizações Internacionais (ONU, COP 15, União Europeia etc.), atuando como delegados e representando diferentes países com sua respectiva política externa. Através de simulações de organismos internacionais, o projeto pretende oferecer aos estudantes secundaristas a oportunidade de debater assuntos conflituosos da agenda internacional, sejam temas sobre questões sociais e humanitárias ou conflitos e crises diplomáticas latentes. O projeto busca desenvolver a análise e o senso crítico de seus participantes, assim como permitir que, através da vivência e da interação com estudantes de diferentes realidades, com pensamentos e atitudes diferentes, estes jovens possam descobrir que o diálogo é sempre a melhor alternativa em uma situação de conflito. Pretende-se, dessa forma, estimular no jovem estudante de ensino médio tanto a capacidade de compreensão dos acontecimentos internacionais, como também a cultura da tolerância. Assim, através de simulações que permitem aos estudantes participarem ativamente das negociações de conflitos internacionais, amplia-se nesses estudantes a capacidade de desmistificar a ideia do "outro", condição fundamental para a cultura da tolerância e para o diálogo entre os diferentes povos.

O projeto tem como base modelos de simulações realizados em diversas universidades brasileiras e estrangeiras, os quais atraem centenas de estudantes interessados nas temáticas a serem debatidas. Ressalta-se, no entanto, que o foco desses projetos são as simulações, através das quais, cada delegado participante, seja graduando ou secundarista, faz a sua inscrição no evento e fica responsável pela sua preparação individual. O SiEM na UFSC, no entanto, tem seu foco na extensão universitária como um elemento fundamental dentro do tripé ensino, pesquisa e extensão. Assim, o objetivo central do projeto é a interação com a comunidade externa, no caso, as escolas de ensino médio da rede pública e privada. Dessa forma, diferentemente de outros projetos de simulação, além de totalmente gratuito, os estudantes que integram a equipe do SiEM responsabilizam-se pela preparação dos secundaristas, o que possibilita que graduandos possam ir para as escolas e transmitir parte do conhecimento adquirido na universidade.

O projeto começou em 2011 e, desde então, o número de escolas participantes amplia-se a cada ano. Em cada nova edição, o projeto recebe novos pedidos de participação de escolas. Em 2020, ocorreria a décima edição do SiEM, mas a crise sanitária impediu que a simulação ocorresse 
de forma presencial e o projeto transformou-se no "SiEM em casa". A expectativa é de que a edição de 2023 possa ocorrer novamente de forma presencial.

\section{DESCRIÇÃO DO PROJETO}

O projeto SiEM da UFSC tem como público-alvo os estudantes de ensino médio das escolas de ensino médio de Santa Catarina e envolve um ano inteiro de trabalho.

Inicialmente, a equipe coordenadora do projeto escolhe os temas a serem abordados e as organizações internacionais nas quais serão realizadas as discussões. Como forma de exemplificar a dinâmica do projeto, cita-se abaixo os temas escolhidos para a nona edição, ocorrida em 2019.

- A Guerra Civil na Síria - tema discutido na Assembleia Geral das Nações Unidas;

- O financiamento ao terrorismo internacional e o protagonismo do Estado islâmico - tema discutido no Conselho de Segurança;

- A questão migratória - tema discutido no Conselho da União Europeia;

- A demarcação de terras dos Guarani Kaiowá - tema discutido na Comunidade de Estados LatinoAmericanos e Caribenhos;

- A crise humanitária que atinge a população Rohingya em Myanmar - tema discutido na Cúpula do Leste Asiático;

- Cúpula dos Objetivos de Desenvolvimento Sustentável da ONU;

- A crise dos refugiados do Sudão do Sul - tema discutido na União Africana

Após a escolha dos temas a serem simulados, inicia-se a execução do projeto, que está dividido em três etapas:

1. Pesquisa sobre os temas a serem debatidos nas simulações e confecção dos materiais de estudo,

2. Visitas e acompanhamento nas escolas e,

3. A realização do evento (as simulações destacadas acima), que ocorre no Centro de Eventos da UFSC ao longo de todo dia.

Após a definição dos temas a serem debatidos e das organizações onde ocorrerão os debates, abrem-se as inscrições para que os estudantes de graduação possam fazer parte da organização de cada uma das três etapas do projeto. Ressalta-se a não obrigatoriedade de que os estudantes estejam envolvidos nas três etapas, sendo facultativo a opção de participar apenas de uma ou duas das etapas, de acordo com seus interesses específicos. Busca-se, dessa forma, o engajamento de 
estudantes que não possuem disponibilidade de tempo para participar de todas as etapas do projeto, mas desejam se envolver com a extensão através da execução de algumas tarefas, de acordo com sua disponibilidade de tempo.

Para a execução da primeira fase (elaboração do material de estudo a ser distribuído nas escolas), os estudantes decidem qual dos temas selecionados gostariam de estudar, formando equipes responsáveis pela pesquisa e pela confecção de um material que, ao final, transforma-se em “apostilas” (os Guias de Estudos e um Guia de Posicionamento Internacionais), que são entregues para as escolas. Cada Guia de Estudo e de Posicionamento explica o conflito em questão e o posicionamento oficial de cada país que participa daquele debate. Por exemplo, os Guias de Estudo e de Posicionamento sobre o debate da questão migratória no âmbito do Conselho da União Europeia apresenta uma problematização da questão e qual tem sido a posição de cada um dos países que pertencem ao Conselho sobre o tema. O objetivo com os Guias é que, partindo desse material, as escolas participem das simulações assumindo realmente a posição do país que representam. Assim, tendo como base as informações disponibilizadas nos Guias produzidos por graduandos, estudantes de ensino médio são estimulados a pesquisar temas centrais da agenda internacional, assim como sobre a cultura e a política dos países que representarão.

$\mathrm{Na}$ segunda etapa do projeto, estudantes de graduação realizam visitas às escolas participantes para apresentar o projeto e definir o número de visitas que serão necessárias em cada escola. O número de visitas por escola varia, normalmente, entre três e oito visitas, de acordo com as necessidades específicas de cada escola. Ao longo das visitas às escolas, graduandos acompanham a preparação dos secundaristas participantes do projeto através de aulas, filmes e debates sobre os temas abordados. Algumas escolas optam por fazer essa preparação internamente (nesse caso, o número de visitas consiste em três), enquanto outras preferem que os graduandos do projeto façam essa preparação (nesse caso, o número de visitas na escola é de aproximadamente oito).

No que diz respeito aos participantes secundaristas, como a demanda por parte das escolas foi se tornando cada vez maior ao longo dos anos, o projeto oferece um número determinado de vagas para cada escola, cabendo a cada uma definir os critérios de seleção interna. Assim, para cada escola oferecemos um determinado número de vagas para delegados de vários países nas diferentes simulações que ocorrerão no evento (Assembleia Geral, Conselho de Segurança, Conselho da União Europeia, União Africana etc.).

Em sua primeira visita às escolas, os estudantes de graduação apresentam também a possibilidade do estudante de ensino médio participar do evento como membro da "Mídia Internacional", cobrindo todas as simulações que ocorrem no dia e divulgando notícias ao longo 
de todo o dia através das redes sociais do evento. Para tal, uma equipe da organização do SiEM (formada somente por estudantes) fica responsável por coordenar as reuniões preparatórias com os secundaristas que optam por participar do evento como "jornalista", cobrindo todas as simulações que ocorrem no dia. As reuniões preparatórias com a "Mídia Internacional" acontecem em laboratórios de informática da UFSC e, nesse caso, são os estudantes secundaristas que se deslocam até a Universidade durante a fase de preparação do evento.

Essas duas primeiras etapas envolveram, em 2019, aproximadamente uns 50 estudantes da graduação e 28 escolas de ensino médio. Dado a crescente demanda das escolas para que os graduandos do projeto ampliem as suas visitas de preparação para o evento, optou-se por realizar, em 2019, o CineSiEM. Essa atividade ocorreu poucas semanas antes da simulação de 2019 e foi organizada pela equipe do SiEM em parceria com uma das redes de cinema de Florianópolis, que disponibilizou gratuitamente as suas salas. O objetivo foi reunir todas as escolas e seus estudantes antes do evento final para uma revisão geral de todos os temas. Assim, durante uma manhã, participantes do projeto SiEM e membros da comunidade externa puderam, com entrada franca, discutir e revisar as temáticas a serem tratadas nas simulações no dia do evento. Devido à forte adesão das escolas participantes e da comunidade externa ao projeto (que entraram nas salas de cinema para escutar os debates), optou-se por manter a atividade para as próximas edições. Infelizmente, a crise sanitária de 2020 iniciou-se na semana que ocorreria novamente o CineSiEM.

A terceira fase do projeto resume-se ao dia do evento, quando ocorrem todas as simulações programadas (Assembleia Geral, Conselho de Segurança, União Africana etc.). Nesse momento, jovens de diferentes escolas encontram-se no Centro de Eventos e na Reitoria da UFSC para desempenhar o papel de diplomatas e jornalistas nas diversas organizações internacionais sobre os temas escolhidos, vivenciando as discussões de forma a exercer sua capacidade de negociação e compreensão das diferentes realidades existentes. Os estudantes são levados a lidar com a resolução de conflitos e a buscar negociações através da diplomacia.

Para que o evento seja bem-sucedido, é necessário montar um cenário que os faça vivenciar a realidade das negociações das organizações internacionais. Esse ponto é fundamental para que os jovens estudantes possam interpretar seu papel e sentirem-se respeitados pelos seu esforço e preparação. Assim, estudantes de graduação também ficam responsáveis pela logística do evento, preparação do espaço e composição das mesas diretoras que regem o andamento das reuniões de cada organização internacional simulada. Ressalta-se que todo o empenho do SiEM para simular o espaço das negociações da maneira mais convincente possível tem sido sempre reconhecida pelas escolas e por seus estudantes que, por sua vez, participam das simulações muito preparados sobre a cultura do país que representam, trazendo diversos elementos interessantes para a simulação. 
Durante todas as fases de sua realização, o SiEM utiliza-se de suas redes sociais para incentivar os participantes e facilitar o contato entre todos, sejam secundaristas ou graduandos. Além disso, aproximadamente um mês antes do evento, o SiEM inicia um projeto chamado "Reta Final", postando para os secundaristas vídeos gravados pela própria organização sobre os temas e atualizando as informações sobre cada debate, de forma a estimular a curiosidade de participantes.

\section{RESULTADOS ALCANÇADOS}

O SiEM conta com a participação e o envolvimento de muitos membros da UFSC e da comunidade externa, embora seu público-alvo seja estudantes de ensino médio da rede pública e privada. Com uma participação crescente, em 2019, o IX SiEM contou com mais de 950 estudantes de ensino médio no dia do evento. No que diz respeito ao envolvimento de graduandos, considerando todas as três etapas de execução, contou-se com a participação de 135 estudantes da graduação.

Ademais, no dia do evento, além da presença dos 950 estudantes secundaristas inscritos e dos graduandos que participaram da organização do evento, contou-se com a presença de representantes institucionais das escolas e visitantes externos interessados no projeto, tais como pais, professores da graduação e de outros colégios não participantes, além de outros estudantes da graduação e membros da comunidade em geral. A partir de uma lista, foi possível registar a presença de 700 pessoas não envolvidas diretamente com o projeto circulando pelos ambientes do evento em 2019.

É possível perceber o crescimento do projeto quando se compara os dados de participação dos estudantes secundaristas na primeira edição do SiEM, em 2011, com a participação na nona edição, em 2019. Do primeiro evento ao nono, a participação dos estudantes de ensino médio aumentou de 250 para 950 estudantes, assim como o número de escolas participantes. A expectativa para 2020 (antes da crise sanitária) era de 1.100 secundaristas.

Quanto à participação dos alunos da graduação, existe uma grande e crescente adesão dos estudantes (inclusive estudantes de outros cursos) como voluntários em todas as etapas do projeto. Muitos graduandos que se envolvem no SiEM já participaram do projeto como estudantes de ensino médio e, após entrarem na UFSC, desejam colaborar com o projeto pelo impacto que a experiência teve na sua formação. Embora o projeto conte com grande entusiasmo por parte dos estudantes de graduação, o principal desafio é a obtenção de bolsas, uma vez que toda a estrutura precisa ser organizada por uma equipe responsável. 
O número de escolas participantes também cresceu ao longo do tempo. O projeto começou com sete escolas, sendo que apenas duas eram da rede pública. Desde então, o esforço do SiEM passou a ser de ampliação da participação de escolas da rede pública. Assim, na edição de 2019, o projeto contou com a participação de vinte e oito escolas das redes públicas e privadas de Florianópolis, São José, Palhoça, Balneário Camboriú e Araranguá, sendo quatorze escolas da rede pública e quatorze escolas da rede privada.

Como resultado, o SiEM vem se consolidando em Santa Catarina como um grande projeto de simulação, aguardado por vários estudantes e escolas. De fato, muitas das escolas já antecipam a realização do evento ao incluir nos seus calendários pedagógicos um espaço para as atividades preparatórias para o SiEM, articulando os temas abordados pelas simulações com suas aulas de história, geografia, redação, português e filosofia.

Além disso, o custo financeiro tornou-se crescente. Assim, embora seja crescente a demanda de novas escolas para participar do projeto e a solicitação de escolas que já participam pelo aumento do número de estudantes envolvidos, tem sido cada vez mais difícil aceitar esses pedidos.

Quanto aos custos financeiros, o projeto necessita de material para fazer placas dos países, crachás dos delegados, blocos de anotações, canetas, bandeiras de países etc. Além disso, como o projeto implica na vinda de secundaristas que passarão o dia inteiro na UFSC, aproveita-se para oferece aos estudantes, principalmente da rede pública, a possibilidade de almoçarem no Restaurante Universitário, necessitando, assim, da compra adiantada de alguns passes do Restaurante Universitário. O maior custo do projeto são dois coffee breaks que ocorrem no dia do evento, um no período da manhã e outro no período da tarde. Os coffee breaks têm um significado relevante no projeto, pois são os momentos nos quais as delegações dos diferentes países podem fazer acordos e negociações, como ocorrem nas negociações oficiais. O projeto é relativamente barato, mas esse custo torna-se cada vez mais alto à medida que o número de estudantes participantes passa de 250 para 950.

\section{CONSIDERAÇÕES FINAIS}

Desde sua origem, o SiEM apresenta-se como um projeto que busca articular a extensão com a pesquisa.

Durante a etapa de elaboração dos guias de estudo, os estudantes do curso de graduação de Relações Internacionais formulam um manual de referência para os professores e estudantes de 
ensino médio. Nesse manual são colocadas todas as informações relevantes para cada debate que ocorrerá no dia do evento:

a) Explicação do tema, definindo as causas que levaram ao conflito. A explicação envolve também uma breve revisão histórica dos países envolvidos no conflito;

b) Posicionamento de cada país que participará da reunião, de acordo com a política externa do país;

c) Regras do funcionamento da tomada de decisão no fórum onde ocorrerá o debate.

A elaboração desse material necessita que os estudantes de graduação se organizem em grupo e desenvolvem pesquisas em diversos assuntos que, embora não sejam abordados em salas de aula, são de interesse de todos os participantes (uma vez que a escolhas dos temas a serem debatidos foi feita por eles).

$\mathrm{Na}$ etapa seguinte (visitas nas escolas), os estudantes de graduação têm a oportunidade de articular suas pesquisas com a extensão, levando o conhecimento adquirido para escolas através de aulas, debates, confecção de material didático (principalmente nas escolas públicas).

Além disso, consideramos que o projeto cumpre uma função relevante dentro da extensão, uma vez que, não apenas trabalha com um público externo à UFSC, mas, ao mesmo tempo, traz esse público para dentro da UFSC. É importante ressaltar que a possiblidade de alunos do ensino médio visitarem a UFSC e almoçarem no Restaurante Universitário é uma oportunidade muito valorizada por todos, uma vez que, para a grande maioria, a UFSC é a opção do futuro.

Em 2020, ocorreria a 10 edição do SiEM, a qual foi inviabilizada pela crise sanitária. Assim, o projeto precisou ser reestruturado para transformar-se no projeto "SiEM EM CASA". A partir desse momento, a equipe do SiEM produziu quatro cartilhas, destinadas principalmente às escolas participantes do projeto, informativas sobre o avanço da pandemia no sistema internacional e dos esforços internacionais em direção aos estudos de uma vacina, que foram divulgadas pelo Instagram.

Os temas das cartilhas foram:

1. Informações gerais sobre o coronavírus;

2. A pandemia no Brasil;

3. A pandemia vista pelas Organizações Internacionais;

4. A pandemia ao redor do mundo.

Em 2021, o SiEM não ocorreu e o mesmo ocorrerá em 2022. Espera-se retomar o projeto em 2023 na forma presencial. 
Relato de experiência do projeto SiEM na UFSC

\section{AGRADECIMENTOS}

Essa é uma experiência escrita por várias mãos. Cada nova equipe do SiEM escreveu um pouco da história desse projeto. Seria impossível nomear e agradecer um por um, pois são dez anos de caminhada. Cada ano, um novo grupo trouxe melhorias e novas ideias para o projeto e todos desempenharam um papel fundamental para a consolidação do SiEM. Gostaria, no entanto, de agradecer especialmente à professora Graciela de Conti Pagliari, que esteve conosco da primeira até a sexta edição e aos, então acadêmicos, Renato Xavier, Lívia Liria Avelhan, Bruno Valim Magalhães e Guilherme Costa. Esses foram os primeiros membros da equipe, que, juntamente com a professora Graciela, participaram do SiEM quando ele era mais uma aventura do que um projeto estruturado, e acabaram por dar o formato inicial que seria a marca do SiEM. Agradeço também aos últimos integrantes do projeto, Carolina Veras Micheletti, Davi Antunes da Luz, Leonardo Felipe Santos de Souza e João Paulo Cavazzani Bosso, que, além da enorme contribuição dada, enfrentaram os desafios impostos ao projeto pela crise sanitária que enfrentamos.

\section{BIBLIOGRAFIA}

DRI, Clarissa; LEITE, Iara. C.; PAGLIARI, Graciela; ARIENTI, Patricia. Experiências alternativas de ensino na UFSC: simulações e contato com atores sociais locais. Meridiano 47, UNB, v. 18, p. 1-17, 2017

ARIENTI, Patricia F. F; PAGLIARI, Graciela. C.. Uma reflexão sobre a prática das Simulações no ensino das Relações Internacionais: um estudo sobre a Simulação para o Ensino Médio. In: X Encontra da Associação Brasileira de Ciência Política, 2016, Belo Horizonte. Ciência Política e a Política: Memória e Futuro, 2016.

Recebido em: 15/11/2021

Aceito em: 09/12/2021 